\title{
Clinical chemistry parameters of piglets at weaning are modulated by an oral, low-dose interferon- $\alpha$ treatment
}

\author{
E. Razzuoli • S. Dotti • I. L. Archetti • M. Amadori
}

Published online: 8 May 2010

(C) Springer Science+Business Media B.V. 2010

\begin{abstract}
Clinical chemistry parameters were investigated in piglets weaned at 22 and 28 days. The effects of an oral, low-dose interferon (IFN)- $\alpha$ treatment at weaning were evaluated as well. The trial was carried out on 59 piglets from the same farm, allocated to three groups: the first and the second groups were weaned at 28 and 22 days of age, respectively; the third group was weaned at 22 days and orally treated at weaning with IFN$\alpha$ at a low dose (1 IU human lymphoblastoid IFN- $\alpha / \mathrm{kg}$ body weight in drinking water) for 10 consecutive days. The results of the field trial confirmed that weaning is one of the main stressing events for pigs at intensive farms. In particular, these findings are based on a dramatic increase in serum haptoglobin levels after weaning in the three groups under study. Results also indicated that early weaning at 22 days implies higher environmental adaptation. In such animals, an oral, low-dose IFN- $\alpha$ treatment gave rise to a peculiar, negative, acute-phase response (reduced levels of serum albumin) and to significantly lower $\alpha$-globulin concentrations in sera. Taken together, IFN- $\alpha$ was shown to modulate inflammatory responses to early weaning stress.
\end{abstract}

Keywords Pig $\cdot$ Weaning $\cdot$ Stress $\cdot$ Clinical chemistry $\cdot$ Interferon- $\alpha$

\begin{tabular}{|c|c|}
\hline Abbrev & ions \\
\hline IFN- $\alpha$ & interferon- $\alpha$ \\
\hline $\mathrm{L} \times \mathrm{Lw}$ & Landrace $\times$ Large White \\
\hline BW & body weight \\
\hline IU & international unit \\
\hline
\end{tabular}

E. Razzuoli $\cdot$ S. Dotti $\cdot$ M. Amadori $(\bowtie)$

Laboratorio di Immunologia Cellulare, Istituto Zooprofilattico Sperimentale della Lombardia e dell'Emilia-Romagna, Brescia, Italy

e-mail: massimo.amadori@izsler.it

I. L. Archetti

Laboratorio di Biochimica Clinica,

Istituto Zooprofilattico Sperimentale della Lombardia e dell'Emilia-Romagna, Brescia, Italy 


\section{Introduction}

The importance of farm animal welfare and its evaluation has been repeatedly highlighted by EU regulations, enacted based on relevant scientific investigations. One of the milestones of the above research activities is the crucial link between innate immune response, inflammation, and stress; most importantly, the inflammatory response was shown to play a fundamental role in the homeostatic control of environmental, infectious, and non-infectious stressors (Amadori 2007). In this respect, weaning is undoubtedly one of the most stressing events at intensive pig farms, as shown by a generalized inflammatory response of enterocytes (Pié et al. 2004). Several factors contribute to the overall stressing effect: feed change, functional immaturity of intestinal epithelial cells, commingling of litters, unfavourable temperature and humidity in the weaning cages, etc. Also, the age of piglets at weaning is a crucial factor that bears on disease occurrence and losses during this phase, which led to the enactment of a legal term of 28 days of age for weaning prescribed by Italian Legislative Decree 20/02/2004 $n^{\circ} 53$. Several lines of evidence demonstrated in fact that early weaning of pigs brings about a strong homeostatic response, including the appearance of interferon- $\alpha($ IFN- $\alpha)$ in serum during the first week after weaning (Amadori 2007; Candotti et al. 2009). In this study, we set out to compare the impact of weaning at 22 and 28 days of age, respectively, as well to evaluate the possible effect of a low-dose, oral IFN- $\alpha$ treatment in pigs weaned at 22 days of age.

\section{Materials and methods}

The study was carried out on 59 Landrace $\times$ Large White $(\mathrm{L} \times \mathrm{Lw})$, randomly selected piglets of six litters in a farrow-to-finish herd in Brescia Province, Italy. Group 1 swine (2 litters, 19 piglets) were weaned at 28 days of age as specified in the above Decree, whereas groups 2 and 3 ( 20 piglets of two litters each) were weaned at 22 days of age. Piglets of group 3 were also orally treated at weaning with human IFN- $\alpha$ in the drinking water for 10 consecutive days (1 IU IFN$\alpha / \mathrm{kg}$ BW daily). The administration of IFN- $\alpha$ was performed by an automatic mixing device to regulate dosing based on water supply requirements of the piglets. All piglets were given a starter feed containing amoxicillin (400 ppm), colistin (120 ppm), and zinc oxide (2000 ppm) over the first 10 days after weaning. Pigs were clinically inspected, and blood samples in vacuum tubes without anti-coagulant were collected at days 0 and +6 with respect to weaning. In the lab, tubes were kept at room temperature for $2 \mathrm{~h}$, refrigerated for $30 \mathrm{~min}$, and then centrifuged at $4^{\circ} \mathrm{C}$ for $15 \mathrm{~min}$ at $2,000 \mathrm{rpm}$; serum was separated and stored in aliquots at $-80^{\circ} \mathrm{C}$. These samples were used in the following determinations: haptoglobin (Kit Phase Haptoglobin, Celbio, Italy, TP 801), cortisol (Kit Cortisol Immulite, Medical System, LKC01), total protein, electrophoretic separation, and densitometry of protein bands (see: http://www.bs. izs.it/Referenza/Benessere/Articoli/Quaderno\%2051.pdf in Italian, for details). Differences between groups were assessed by one-way ANOVA, whereas time-related changes in the same subjects were analyzed by a paired $t$ test (Prism 2.01, GraphPad Software, San Diego, CA). The significance threshold was set at $P<0.05$.

\section{Results}

Results obtained on sera collected at days 0 and +6 with respect to weaning are shown in Table 1. Haptoglobin levels significantly increased at day +6 in all piglets $(P<0.01$ in all 
Table 1 Clinical chemistry parameters observed in sera of piglets before and after weaning. Results are expressed as means \pm 1 standard deviation. Delta corresponds to the difference between mean values of days 0 and +6 . Group 1: weaned at 28 days. Group 2: weaned at 22 days. Group 3: weaned at 22 days and submitted to an oral, low-dose IFN- $\alpha$ treatment

\begin{tabular}{llccc}
\hline Parameters & Unit & Day 0 & Day +6 & Delta \\
\hline Haptoglobin Group 1 & $\mathrm{mg} / \mathrm{mL}$ & $0.51 \pm 0.9$ & $2.28 \pm 1.22$ & 1.77 \\
Haptoglobin Group 2 & $\mathrm{mg} / \mathrm{mL}$ & $0.17 \pm 0.45$ & $0.98 \pm 0.54$ & 0.81 \\
Haptoglobin Group 3 & $\mathrm{mg} / \mathrm{mL}$ & $0.15 \pm 0.23$ & $1.28 \pm 0.91$ & 1.13 \\
Cortisol Group 1 & $\mathrm{ng} / \mathrm{mL}$ & $1.65 \pm 1$ & $3.38 \pm 1.75$ & 1.73 \\
Cortisol Group 2 & $\mathrm{ng} / \mathrm{mL}$ & $2.21 \pm 1.18$ & $2.88 \pm 1.42$ & 0.67 \\
Cortisol Group 3 & $\mathrm{ng} / \mathrm{mL}$ & $2.32 \pm 1.24$ & $3.35 \pm 1.68$ & 1.03 \\
Total protein Group 1 & $\mathrm{g} / \mathrm{L}$ & $45.11 \pm 3.77$ & $48.89 \pm 4.06$ & 3.78 \\
Total protein Group 2 & $\mathrm{g} / \mathrm{L}$ & $45.5 \pm 3.50$ & $45.37 \pm 3.13$ & -0.13 \\
Total protein Group 3 & $\mathrm{g} / \mathrm{L}$ & $50.6 \pm 4.30$ & $46.95 \pm 7.55$ & -3.65 \\
Albumin Group 1 & $\mathrm{g} / \mathrm{L}$ & $23.93 \pm 1.91$ & $25.28 \pm 2.58$ & 1.35 \\
Albumin Group 2 & $\mathrm{g} / \mathrm{L}$ & $24.21 \pm 2.10$ & $24.25 \pm 2.40$ & 0.04 \\
Albumin Group 3 & $\mathrm{g} / \mathrm{L}$ & $28.82 \pm 1.35$ & $25.72 \pm 2.20$ & -3.1 \\
$\alpha$-globulins Group 1 & $\mathrm{g} / \mathrm{L}$ & $9.01 \pm 0.97$ & $11.40 \pm 1.05$ & 2.39 \\
$\alpha$-globulins Group 2 & $\mathrm{g} / \mathrm{L}$ & $8.64 \pm 0.76$ & $10.05 \pm 1.08$ & 1.41 \\
$\alpha$-globulins Group 3 & $\mathrm{g} / \mathrm{L}$ & $9.08 \pm 0.96$ & $9.54 \pm 1.30$ & 0.46 \\
$\beta$-globulins Group 1 & $\mathrm{g} / \mathrm{L}$ & $7.31 \pm 0.8$ & $7.64 \pm 0.8$ & 0.33 \\
$\beta$-globulins Group 2 & $\mathrm{g} / \mathrm{L}$ & $6.55 \pm 1.03$ & $6.4 \pm 0.94$ & 0.15 \\
$\beta$-globulins Group 3 & $\mathrm{g} / \mathrm{L}$ & $7.88 \pm 1.57$ & $6.85 \pm 1.3$ & -1.03 \\
$\gamma$-globulins Group 1 & $\mathrm{g} / \mathrm{L}$ & $4.8 \pm 1.03$ & $4.5 \pm 0.7$ & -0.3 \\
$\gamma$-globulins Group 2 & $\mathrm{g} / \mathrm{L}$ & $6.09 \pm 2.9$ & $4.66 \pm 2.12$ & -1.43 \\
$\gamma$-globulins Group 3 & $\mathrm{g} / \mathrm{L}$ & $5.82 \pm 1.94$ & $4.83 \pm 1.43$ & -0.99 \\
\hline & & & &
\end{tabular}

groups). Cortisol levels were also on the rise with the highest levels observed in group 1 $(P<0.001$; non-significant differences in groups 2 and 3$)$. Total protein levels were stable in group 2, as opposed to both groups $1(+3.78 \mathrm{~g} / \mathrm{L}, P<0.001)$ and $3(-3.65 \mathrm{~g} / \mathrm{L}, P<0.001)$. Serum albumin levels showed minor changes in groups 1 and 2 , whereas a significant decrease $(P<0.001)$ was observed in group 3. A significant increase of $\alpha$-globulin levels $(P<0.001)$ was seen in groups 1 and 2 , as opposed to group 3 . $\beta$-globulin levels significantly decreased in group 3 only $(P<0.001)$, whereas levels were substantially stable in groups 1 and 2. $\gamma$-globulin levels were shown to decrease in all groups, with significant differences in groups 2 and $3(P<0.001)$.

\section{Discussion}

The results of the field trial confirm that weaning is one of the main stressing events for pigs at intensive farms. In particular, this conclusion is founded on the dramatic increase of serum haptoglobin levels after weaning in the three groups under study. In fact, haptoglobin is produced by the liver as a response to inflammatory conditions, infectious and noninfectious stressors as part of a global, positive acute-phase response. Overall, high haptoglobin levels in the three groups confirm that weaning causes a pronounced inflammatory response in piglets. 
Serum cortisol levels significantly increased in group 1 only because of a more vigorous adrenal adaptive response compared with pigs weaned at 22 days of age. Additionally, this result is in agreement with another study of ours, which highlighted increased serum levels of inflammatory cytokines in piglets weaned at 22 days of age (Candotti et al. 2009).

The lower levels of serum albumin and $\alpha$-globulins in sera of IFN- $\alpha$-treated piglets can be accounted for by a peculiar negative acute-phase response and stability of concentrations, respectively. On the contrary, a significant increase of $\alpha$-globulins in groups 1 and 2 was probably dictated by a greater requirement for both $\alpha_{1}$-antitrypsin and $\alpha_{2}-$ macroglobulin to control the inflammatory conditions after weaning.

The negative acute-phase response in IFN- $\alpha$-treated piglets is probably relevant to the decrease of $\beta$-globulin levels too, keeping in mind the role of transferrin as a negative acute-phase reactant. Instead, the changes in $\gamma$-globulin levels of the three groups do not seem to be related to weaning. In fact, $\gamma$-globulins usually decrease between days 14 and 28 , and level off until 56 days of age following the decay of colostrum-derived antibody (Martin et al. 2005).

In conclusion, our results indicate that piglets weaned at 28 days of age show a stronger homeostatic control compared with piglets weaned at 22 days of age. Furthermore, piglets weaned at 22 days and orally treated with IFN- $\alpha$ showed a better adaptive response compared with age-matched control animals. The regulatory action of IFN- $\alpha$ is mainly directed to a control of the IFN- $\gamma$ gene (Amadori et al. 2009), which is accounted for by the dramatic increase of IFN- $\gamma$-secreting lymphocytes in lamina propria in the first week after weaning (Vàzquez et al. 2000). Interestingly, the better adaptive response of IFN- $\alpha$-treated pigs is confirmed by their greater daily mean weight gain after weaning (Candotti et al. 2009).

Acknowledgements The authors want to thank Dr. Paolo Candotti (IZSLER, Brescia, Italy) for his excellent co-operation in blood samplings. This study was supported by the Italian Ministry of Health, grant PRC2005002.

\section{References}

Amadori M (2007) The role of IFN- $\alpha$ as homeostatic agent in the inflammatory response: A balance between danger and response? J Interferon Cytokine Res 27:181-189

Amadori M, Farinacci M, Begni B, Faita R, Podavini D, Colitti M (2009) Effects of interferon- $\alpha$ on the inflammatory response of swine peripheral blood mononuclear cells. J Interferon Cytokine Res 29:241247

Candotti P, Rota Nodari S, Razzuoli E, Dotti S, Amadori M (2009) Verifica degli effetti flogistici dello svezzamento precoce nel suinetto e loro modulazione mediante somministrazione di interferon-alfa. Atti Convegno SIPAS 35:293-299

Martin M, Tesouro MA, Gonzàlez-Ramòn N, Piñeiro A, Lampreave F (2005) Major plasma proteins in pig serum during postnatal development. Reprod Fertil Dev 17:439-445

Pié S, Lallès JP, Blazy F, Laffitte J, Sève B, Oswald IP (2004) Weaning is associated with an upregulation of expression of inflammatory cytokines in the intestine of piglets. J Nutr 134:641-647

Vàzquez E, Gil A, Garcia-Olivares E, Rueda R (2000) Weaning induces an increase in the number of specific cytokine-secreting intestinal lymphocytes in mice. Cytokine 12:1267-1270 